\title{
La participación popular bajo el prisma de la comparación de casos contrastados: asociacionismo y política en las afueras de París y Buenos Aires (1930-2010)
}

Working-class participation through the method of contrast-oriented comparison: associationism and politics in the suburbs of Paris and Buenos Aires (1930-2010)

Arnaud Trenta

DOI: https://doi.org/10.24215/18537863e070

Institut de Recherches Economiques et Sociales (IRES),

Francia

arnaudtrenta@hotmail.com

Recepción: 22 Marzo 2019

Aprobación: 03 Febrero 2020

\section{Resumen:}

El objetivo del artículo es iluminar los aportes de la comparación de casos fuertemente contrastados a partir de una investigación sobre las prácticas asociativas en barrios populares de la periferia urbana de París y Buenos Aires. La primera parte expone el marco de la comparación y la construcción del objeto de investigación. La segunda parte da cuenta de las similitudes y diferencias que se establecen en la formación de esos dos suburbios industriales y sus consecuencias en las formas de sociabilidad popular local entre los años 1930 y 1970. La tercera parte analiza las transformaciones sociales, económicas y políticas que generan a partir de los años 1980, tanto en Francia como en Argentina, una mayor participación de los sectores populares en las asociaciones territoriales. La conclusión retoma los resultados generales que se desprenden de esta investigación comparativa y subraya los principales aportes del método de casos muy diferenciados.

Palabras clave: Comparación de Casos Contrastados, Francia, Argentina, Participación, Clases Populares.

\section{Abstract:}

The article aims to illuminate the contributions of contrast-oriented method from an investigation on the transformations of working-class participation in the suburbs of Paris and Buenos Aires (1930-2010). The first part sets out the framework of the comparison and the construction of the object of the investigation. The second part gives an account of the analysis of the similarities and differences in the forms of working-class sociability in both industrial suburbs (1930-1970). The third part illustrates the contribution of the comparison to analyse the increase of grassroots participation of the working-class in relation with the disaggregation of industrial society (1970-2010). The conclusion underlines the benefits of the method of contrastoriented comparison to the researcher's reflexivity and creativity.

KEYwORDs: Contrast-Oriented Method, France, Argentina, Participation, Working-Class.

Desde hace varias décadas, las investigaciones comparativas en ciencias sociales han conocido, a la vez, un crecimiento y una diversificación de sus prácticas. En el contexto de la globalización que intensifica la disputa entre las naciones y el peso de las gobernanzas supranacionales (Giraud, 2012), numerosas contrataciones públicas fueron dirigidas al mundo académico para realizar comparaciones internacionales con el propósito de dotar de una mayor racionalización y competencia a los sistemas sociales y las políticas públicas. Si bien este contexto ha generado un flujo de demandas de análisis comparativos más o menos orientadas hacía fines políticos, el entusiasmo contemporáneo por las investigaciones comparativas se vincula también a razones académicas instituidas en el largo plazo. Dentro de la sociología, por ejemplo, la capacidad heurística de la comparación ha sido subrayada desde los fundadores de la disciplina, tanto en los estudios de Émile Durkheim (1895 y 1897) como en aquellos de Max Weber (1996, 2001 [1909] y 2014 [1922]). La originalidad del periodo actual reside en un relativo declive de las grandes escuelas del comparativismo y una 
diversificación de los terrenos, objetos, métodos y teorías de la comparación (Demazière, Giraud y Lallement, 2013).

Las tradiciones durkheimianas y weberianas constituyeron, durante largo tiempo, dos lógicas opuestas dentro del campo de los estudios comparativos que planteaban, por un lado, una predisposición a la universalización de los objetos de investigación, al análisis deductivo y a la focalización sobre las variables y, por otro lado, una propensión a la individualización de los objetos de investigación, al análisis inductivo y a la focalización sobre los casos (Giraud, 2003). La lógica durkheimiana centrada en las variables integra un gran número de casos que permiten, por medio de metodologías cuantitativas, probar hipótesis generales que deriven de la teoría. La aproximación weberiana, al contrario, se basa sobre un número limitado de casos que son analizados en profundidad mediante métodos cualitativos y restituidos en sus contextos a fin de dar cuenta de la complejidad del mundo social. Ahora bien, desde la década de 1980 se observa una superación de estos clivajes y la búsqueda de una alternativa al dualismo entre el "universalismo nominalista y el particularismo culturalista" (Théret, 1997, p. 166). La comparación internacional se encuentra entonces menos sometida a una metodología o un paradigma en particular (Hassenteufel, 2000) y se asemeja a una "estrategia de investigación" que se elabora a partir de los problemas estudiados y las especificidades de los terrenos empíricos (Lallement y Spurk, 2003). Sin embargo, el enfoque comparativo mantiene una exigencia de reflexividad en torno a la construcción del objeto de investigación y el manejo de la comparación de datos (Lallement, 2003).

Estos cambios en las prácticas comparativas y el contexto en el que se inscriben generan múltiples desafíos para los investigadores, tales como el cuestionamiento del espacio nacional como marco "natural" de la comparación, la variedad de juegos de escalas necesarios para la comprensión de mecanismos sociales que se definen en todos los niveles y la tensión entre lo singular y lo universal que crece con la diferenciación de los casos comparados. En un contexto signado por la globalización, la comparación de casos muy diferentes reviste de cierta actualidad (Cefaï, 2007; Giraud, 2012; Kocka, 2013), aunque la comparación de los casos similares en tiempo y espacio (Bloch, 1928) sigue siendo dominante en las ciencias sociales. El análisis de casos contrastados, puesto en valor por Clifford Geertz (1968, 1983, 1998), está sin embargo en el fundamento mismo de la metodología comparativa e incluso explora sus límites. Este enfoque ejerce "una tensión" sobre las categorías analíticas "que puede ser resuelta solamente por medio de su reconstrucción y de la verificación de que funcionan en ellas mecanismos conmensurables, a pesar de la diversidad de las situaciones concretas" (Giraud, 2012, p. 90). “Comparar lo incomparable” (Détienne, 2000) constituye aún un desafío para la investigación que no puede ser asumido sin el aporte de la mirada reflexiva.

El objetivo de este artículo es iluminar los aportes de la comparación de casos fuertemente contrastados para el análisis de transformaciones sociopolíticas ocurridas durante las últimas décadas, particularmente las formas de sociabilidad y participación política de los sectores populares. A partir de un trabajo empírico en las periferias de París y Buenos Aires, el paper pone en evidencia una serie de factores que demuestran la centralidad adquirida por las organizaciones sociales en las configuraciones sociopolíticas de los territorios populares urbanos. La primera parte expone el marco de la comparación y la construcción del objeto de investigación. La segunda parte da cuenta de la manera en que se analizaron las similitudes y diferencias en la formación de esos dos suburbios industriales y sus consecuencias en las formas de sociabilidad popular local entre los años 1930 y 1970. La tercera parte muestra cómo se relacionó a las grandes transformaciones sociales, económicas y políticas, que afectan a ambos casos a partir de los años 1980, con una mayor participación de los sectores populares en las asociaciones territoriales. La conclusión retoma los resultados generales que se desprenden de esta investigación comparativa y subraya los principales aportes del método de casos muy diferenciados. 


\section{LA PARTICIPACIÓN ASOCIATIVA EN PERSPECTIVA COMPARADA}

\subsection{El espacio asociativo como revelador de reconfiguraciones políticas}

La investigación parte de un cuestionamiento general sobre el rol de las asociaciones en el funcionamiento democrático. Desde la década de 1970, las sociedades occidentales en su conjunto están atravesadas por un doble proceso de deslegitimación de las instituciones representativas y de valoración de las organizaciones de la sociedad civil. Desde la filosofía política, y más precisamente el heterogéneo pensamiento antitotalitarista francés (Aron, 1965; Castoriadis, 1973; Lefort, 1981), este proceso sociohistórico puede interpretarse como una reconfiguración de lo político ligada a una nueva inversión de la relación entre el Estado y la sociedad civil que otorga a esta última el protagonismo en el progreso socioeconómico y el devenir histórico. Retomando la teoría política de Marcel Gauchet $(1985,2003$, 2005), actual representante de la corriente antitotalitarista, concebimos la modernidad democrática como la "revolución de la autonomía" (Gauchet, 2007a), es decir el proceso de salida de la heteronomía religiosa de las sociedades tradicionales que se manifiesta por medio de la paulatina desvinculación de los individuos y el despliegue de una estructuración autónoma de las comunidades políticas. En esta perspectiva, las asociaciones libres, voluntarias e igualitarias son un rasgo característico de la modernidad democrática y una herramienta de la constitución de comunidades políticas autónomas, particularmente por su rol en la formación de un espacio público amplio y diverso cuya función es la intermediación entre el Estado y la sociedad civil. En el contexto de crisis del Estado proveedor, de fracaso de las experiencias comunistas y de dominación de la ideología neoliberal, las creencias modernas en la potencia de autoconstitución de la sociedad civil y en el mito de la superación de lo político han retomado relevancia (Gauchet, 2001), lo que desemboca en la consagración de la figura del individuo a través el derecho y el mercado, y la reducción del aparato de la acción publica a una gobernanza inofensiva (Gauchet, 2007b, 2010, 2017). Este eclipse de lo político tapa en realidad una nueva configuración del Estado que, lejos de desaparecer, ocupa una posición infraestructural y crea las condiciones de la reactivación del proceso de liberalización de los individuos y las organizaciones de la sociedad civil (empresariales como asociativas) en todos los dominios de la vida colectiva.

Con el propósito de dialogar con la filosofía política y articularla a la sociología empírica, la investigación se focaliza en las interacciones entre las asociaciones y las instituciones políticas para analizar las cambiantes relaciones entre el Estado y la sociedad civil. La ambición de la comparación internacional consiste en iluminar procesos sociales similares vinculados a las transformaciones de lo político y lo asociativo, sin perder de vista las diferencias observables entre los casos nacionales. Poner en el mismo plano casos tan contrastados como Francia y Argentina -generalmente estudiados desde una perspectiva Norte/Sur o Centro/Periferiapermite explorar los límites del espacio cultural occidental y su dinámica histórica. De esta manera, la pesquisa se propone también ser una contribución al diálogo transatlántico sobre las semejanzas entre las sociedades europeas y latinoamericanas (Guerra, 2002; Compagnon, 2009; Kessler y Merklen, 2013).

A pesar de las grandes diferencias en términos políticos, históricos, económicos y demográficos, la comparabilidad entre Francia y Argentina aparece más factible cuando el análisis se focaliza sobre la historia reciente de las organizaciones intermediarias, tales como los partidos políticos, los sindicatos y las asociaciones. En ambos casos nacionales se observa que los partidos políticos se enfrentan con una disminución de las adhesiones y una menor fidelización de los electores (Manin, 1995; Torre, 2003, 2017). Los sindicatos de trabajadores conocen también ciertas dificultades similares -a pesar de una notable recuperación de las organizaciones gremiales durante la última década en Argentina- ligadas al descenso del número de sus militantes y la fragmentación cada vez más importante del campo sindical (Andolfatto, 2007; Murillo, 2005; Etchemendy, 2013). No obstante, la perdida de centralidad de estas organizaciones representativas no se relaciona con una desilusión en torno a la democracia, tampoco con un desinterés por la cosa pública. En Francia como en Argentina, la variedad de dispositivos públicos y movilizaciones 
ciudadanas subrayan la importancia de las aspiraciones a la participación política de manera más regular y directa que la simple elección de representantes (Bevort, 2002; Bacqué, Rey y Sintomer, 2005; Rosanvallon, 2006; Schuster, Naishtat, Nardacchione y Pereyra, 2006; Svampa, 2008; Annunziata, 2015). Dentro de las organizaciones que encarnan este "nuevo espíritu de la democracia" (Blondiaux, 2008), las asociaciones constituyen un extenso y heterogéneo espacio social que cambió profundamente a partir de los años 70 (Roitter y Bombal, 2000; Di Stefano, Sabato, Romero y Moreno, 2002; Rosanvallon, 2004; Hély, 2009; Laville, 2010). Mientras los compromisos militantes sindicales y políticos disminuyeron, las organizaciones sociales conocieron un incremento numérico muy elevado y adquirieron una mayor legitimidad en el funcionamiento democrático.

\subsection{La participación asociativa en los barrios populares}

La participación asociativa es la categoría analítica escogida para realizar la comparación del rol de las organizaciones sociales en la vida pública de ambos países, la cual se define como el involucramiento deliberado de los individuos en grupos relativamente estables que intervienen en el espacio público (Barthélemy, 2000). La dimensión deliberada de la implicación individual hace referencia a la idea de asociaciones libres, voluntarias e igualitarias propia de la democracia moderna. La estabilidad de los grupos permite distinguir las asociaciones de las movilizaciones más efímeras y pensar la participación individual en términos de militancia. La intervención en el espacio público inscribe a las organizaciones sociales en los procesos de publicización de problemas sociales, lo que amplía el espectro de la participación democrática más allá de la política institucional tal como lo demuestra la sociología de los problemas públicos (Spector y Kitsuse, 1977; Blumer, 2004 [1971]; Gusfield, 2009 [1981]; Dewey, 2010 [1927]; Cefaï y Terzi, 2012; Pereyra, 2013). En síntesis, la participación asociativa expresa la capacidad de los actores sociales a percibir las situaciones consideradas como problemáticas, a movilizarse para definir cuál es el problema y quiénes son los responsables, y a interactuar con los poderes públicos en vistas a la resolución de dichas situaciones.

La investigación se construyó luego a partir de un enfoque local, con el fin de captar las lógicas territoriales de la acción asociativa. El espacio local resulta fecundo para estudiar las nuevas formas de militancia que se caracterizan por un anclaje territorial, una reivindicación de autonomía y una participación directa (Ion, 1997, 2012; Svampa, 2008 y 2011). Lo local no está considerado como un objeto en sí mismo sino como un "espacio de investigación" que ilumina transformaciones más generales (Briquet y Sawicki, 1989), lo que implica una articulación de las distintas escalas de análisis como el barrio, el municipio, la provincia y la nación (Authier, Bacqué y Guérin-Pace, 2007). La pesquisa se centró finalmente en los territorios de sectores populares con el objetivo de interrogarse sobre las formas de sociabilidad y militancia de las clases populares en el contexto de la desagregación del mundo obrero y la estigmatización de los barrios pauperizados (Beaud y Pialoux, 1999; Merklen, 2009; Schwartz, 2011; Kessler, 2012). El trabajo de investigación en los barrios populares de las periferias de París y Buenos Aires entonces permitía vincular el estudio de las asociaciones y los sistemas políticos locales con la historia de los suburbios industriales.

Los barrios elegidos forman parte de las ciudades de Gennevilliers y Tres de Febrero, ubicadas respectivamente en la pequeña corona de las afueras parisinas y el primer cordón del conurbano bonaerense. Estas dos ciudades no están aisladas de los grandes centros urbanos, al contrario, sus territorios están atravesados por las distintas redes del transporte público vial y ferroviario que facilitan la movilidad de los habitantes y los trabajadores. Comparten igualmente ciertas características históricas, demográficas y políticas como, por ejemplo, sus procesos de urbanización que se inician durante la primera mitad del siglo XX con la instalación de talleres y fábricas de tamaño muy diverso y la construcción de viviendas destinadas a trabajadores de bajos ingresos (Dupuy, 2003; Rougier y Pampin, 2015). A pesar de la desindustrialización que ha afectado a ambos países, la demografía de estas ciudades se caracteriza todavía por una mayoritaria presencia de las categorías de obreros y empleados: $59 \%$ de la población activa en Gennevilliers y 67 \% de la 
población activa en Tres de Febrero. ${ }^{1}$ Por otro lado, estos territorios forman parte de los bastiones históricos de los principales partidos ligados a la clase obrera, es decir el partido comunista en Francia y el partido peronista en Argentina. El municipio de Gennevilliers ha sido gobernado sin discontinuidad por elencos comunistas desde el año 1935 y los dirigentes peronistas locales ganaron casi todas las elecciones en Tres de Febrero a partir del retorno a la democracia en $1983 .{ }^{2}$ Estos territorios se inscriben entonces en unas historias colectivas más amplias que permiten articular el análisis de la participación asociativa al nivel local con las transformaciones de las modalidades del compromiso político de las clases populares.

\subsection{La inscripción de las asociaciones en configuraciones políticas locales}

La comparación de la participación asociativa en los barrios populares de Gennevilliers y Tres de Febrero corresponde a una "estrategia de investigación" inspirada de las aproximaciones institucionalistas (Lallement y Spurk, 2003). Estas aproximaciones ponen de relieve la comparación de sistemas o configuraciones que vinculan las prácticas y representaciones de los actores con los recursos y las obligaciones de las instituciones. La categoría analítica central en la comparación está relacionada con las distintas instituciones que le confieren su alcance societal. Como lo sugiere Michel Lallement,

son los conjuntos, sistemas, configuraciones... -llamémoslo como queramos- que son interesantes para la observación, dado que lo esencial no está en la naturaleza de un elemento sino en su presencia o ausencia, y más aún, en su posicionamiento relativo a dentro de un espacio de interacciones. En materia de comparaciones internacionales, nunca un imperativo de estas características habría sido tan pertinente: el estudio de las relaciones entre actores, instituciones, repertorios retóricos, registros de acción colectiva... prevalece sobre la atención a una entidad singular que, considerada de manera aislada, no enseña nada al observador (Lallement, 2003, p. 298).

El análisis de la participación asociativa en los barrios populares se focaliza entonces en el espacio de interacciones constituido por las organizaciones sociales y las instituciones políticas. La actividad de las asociaciones está relacionada con los poderes públicos y los partidos políticos en el marco de configuraciones políticas locales (Sawicki, 1997). La ubicación de las asociaciones en estas configuraciones adquiere toda su pertinencia cuando es analizada desde una perspectiva diacrónica. La perspectiva histórica permite comprender los cambios ocurridos en las configuraciones políticas y evitar el escollo de la reificación.

El trabajo de campo de tipo etnográfico se realizó principalmente con militantes de organizaciones sociales, pero también con funcionarios municipales vinculados al sector asociativo y militantes políticos presentes en los barrios. En total, de 2008 a 2012, se realizaron 79 entrevistas en profundidad y numerosas observaciones de situaciones formales e informales en las asociaciones, las administraciones municipales y los partidos políticos. La primera fase de la encuesta sirvió para localizar una diversidad de asociaciones que intervienen en el espacio público local en ambas ciudades y poner a la luz un mapa general de los distintos vínculos que las unen a las instituciones políticas. En la segunda fase, el análisis se focalizó sobre cuatro casos de asociaciones con el fin de profundizar, por un lado, las relaciones entre las organizaciones sociales y el Estado a través de la puesta en marcha de políticas sociales territorializadas ${ }^{3} y$, por otro lado, las relaciones entre las asociaciones y los partidos políticos en la movilización de los vecinos. ${ }^{4}$

Este artículo se focaliza sobre el rol de las asociaciones en las políticas sociales territorializadas a partir de los años 80, lo que conlleva a analizar la participación asociativa en los barrios populares en relación con los procesos de desindustrialización, de desagregación del mundo obrero y de pauperización de las clases populares. Se estudia entonces el modo en que estos procesos modifican las configuraciones políticas locales y las formas de sociabilidad en los territorios populares, y en qué medida estos cambios generan más acciones colectivas ligadas al tejido asociativo. En esta perspectiva, la segunda parte del texto pone a la luz la manera en que el análisis reveló diferencias sustantivas a nivel de las configuraciones políticas y las sociabilidades populares en las afueras de París y Buenos Aires entre los años 1930 y 1970. La tercera parte da cuenta de la 
aproximación teórica-metodológica que permite iluminar los mecanismos similares que favorecieron durante las tres últimas décadas una mayor participación asociativa en estos territorios fuertemente contrastados. De este modo, el análisis ilustra la tensión inherente al enfoque comparativo entre lo singular y lo universal, que es particularmente más compleja en el método de los casos muy diferentes.

\section{Sociabilidad LOCAL EN LAS PERIFERIAS INDUSTRIALES DURANTE EL SIGLO XX}

Para estudiar las configuraciones políticas y las sociabilidades locales en los territorios populares en el periodo previo a la encuesta empírica, el análisis se basó en dos tipos de material: los trabajos académicos referentes sobre la cuestión y las entrevistas de actores sociales con una larga trayectoria de militancia. Por un lado, se realizó un estado del arte a partir de la literatura historiográfica y sociológica de ambos países, especialmente aquella que ponía énfasis sobre las prácticas asociativas y sus relaciones con la política. Por otro lado, ciertas entrevistas con militantes muy activos en la vida política local permitieron articular los datos generales provenientes de la literatura con la experiencia vivida de los actores sociales, particularmente en relación con las modalidades de la acción colectiva en estos territorios.

\subsection{Banlieue rouge y sistema comunista}

En Francia, el desarrollo industrial está marcado por la instalación de grandes fábricas en la periferia de las principales ciudades a partir de mediados del siglo XIX. En Gennevilliers, a pesar de la perduración del cultivo de productos hortícolas, la localidad se transformó paulinamente en un espacio industrial poblado de fábricas, talleres, galpones y depósitos. En términos generales, los suburbios industriales que emergieron en la periferia de París a comienzos del siglo XX se constituyeron por fuera de las grandes políticas urbanísticas y fueron el resultado de arreglos privados desfavorables para las poblaciones que se radicaron en esos territorios. El periodo de entreguerras está caracterizado por la figura del mal-loti, es decir, el trabajador humilde que puebla las nuevas zonas loteadas que carecen de infraestructuras colectivas como la pavimentación de las calles y el alumbrado público. La historiografía reciente ha demostrado cómo las condiciones de trabajo fueron también menos favorables en estos suburbios industriales en donde "los salarios son más bajos que en París, la disciplina más dura, la taylorización más precoz que en los talleres parisinos o lioneses” (Fourcaut, 2007, p. 8). La concientización de estos problemas condujo a los primeros triunfos electorales del Partido comunista francés (PCF) en los años 1920 y su implantación duradera en las afueras de París desde los años 1930 (Courtois y Lazar, 1995). En Gennevilliers como en otros suburbios industriales de la banlieue rouge, el "comunismo municipal" dejó sus huellas sobre esos territorios que se transformaron en "verdaderas ciudades" (Fourcaut, 1986). Las políticas municipales comunistas se tradujeron particularmente en la creación de escuelas, de colonias de vacaciones, de espacios culturales, de centros de salud y de baños públicos, al igual que en el mejoramiento de la red vial y de la renovación del parque inmobiliario. Durante varias décadas, las ciudades comunistas fueron lugares de promoción social y cultural de las clases populares que contribuyeron localmente a la consolidación de la clase obrera a través de ese trabajo político de valorización de grupo (Masclet, 2003).

Si el término banlieue rouge corresponde a la toma del poder local por parte del partido comunista, esta noción expresa también la conformación de un modelo de "contra sociedad" al capitalismo burgués (Kriegel, 1968; Pudal, 1989) que se manifiesta a través de una forma de sociabilidad local caracterizada por una estrecha relación entre las organizaciones políticas, sindicales y asociativas. En las ciudades obreras que conformaban la banlieue rouge parisina, la fuerte homogeneidad social como la relación casi simbiótica entre la fábrica y el barrio dieron lugar a configuraciones políticas locales tan estructuradas que se pueden analizar en términos de sistema social. En grandes rasgos, el sistema social de la banlieue rouge articulaba tres lógicas 
de acción: "una lógica comunitaria construida en torno a una cultura popular, una lógica de consciencia de clase y, por fin, una lógica de participación social constituida alrededor de los partidos, los sindicatos y las asociaciones" (Dubet y Lapeyronie, 1992, pp. 49-50). No obstante, en el seno de las ciudades obreras comunistas, las organizaciones políticas y sindicales representaban los principales espacios de militancia, mientras que las asociaciones ocuparon una posición subalterna en las configuraciones políticas. Controladas por las organizaciones comunistas, las asociaciones sirvieron principalmente de relevo para los elegidos y militantes con el objeto de encuadrar y politizar el conjunto de la vida social local.

El intendente, los elegidos, los militantes comunistas son, gracias a la multiplicidad de asociaciones y a la diversidad de sus manifestaciones, omnipresentes en la vida local: ellos presiden las fiestas, los bailes, los desfiles, están en contacto con todos los sectores de la población por medio de asociaciones especializadas, aparecen como los organizadores de todos los divertimentos. Sus roles dejan de ser percibidos como exclusivamente políticos, y la adhesión a las ideas que propagan se convierte en el corolario masivamente compartido de la participación a la vida de relaciones de la comuna (Fourcaut, 1986, pp. 159-160).

En síntesis, al interior del suburbio industrial parisino, el vínculo al trabajo y a la política era central en la sociabilidad local de las clases populares. La militancia comunista en el sindicato y el partido estructuraba la sociabilidad de la banlieue rouge, y las asociaciones se incorporaban de manera limitada en este sistema vertical a través de actividades sectoriales (fiesta, deporte, juventud, etc.).

Este sistema de acción funcionó hasta los años 1970-1980 como lo relatan varios dirigentes sociales y políticos de la ciudad de Gennevilliers. La presidenta de la asociación de jardines infantiles que hemos estudiado se instaló en un monoblock de la ciudad en 1973 y empezó a militar de ahí en adelante con su marido para fomentar lazos de solidaridad entre familias, y particularmente entre madres amas de casa. Originarios de familias obreras, esta pareja participó en su juventud en diversas organizaciones vinculadas al catolicismo social y el movimiento de educación popular, y realizó su militancia en los barrios populares a través de la red de la Unión Nacional de las Asociaciones Familiares sin jamás afiliarse a ningún partido político. A poco tiempo de su presencia en Gennevilliers, pese a la falta de servicios públicos en la zona, la pareja había fomentado un grupo de vecinos del monoblock en torno a la guardia compartida de los niños y otras actividades de ayuda mutua, pero este activismo alertó a los militantes comunistas que se alojaban en el gran conjunto residencial y que lograron rápidamente controlar la flamante acción colectiva.

En aquel momento, el partido comunista estaba muy presente. No tengo nada en contra del partido comunista, pero hay métodos que no me gustan... que no me gustaban en aquella época. El partido comunista ha cambiado profundamente y hoy en día tenemos gente que aceptan la diferencia, lo que no era el caso en aquella época. Si podían cortar las piernas a alguien, lo hacían... Y nosotros, en nuestro edificio, teníamos a dos militantes comunistas. A la primera reunión del monoblock participaron 62 vecinos y la gente del partido comunista vino para proponer la formación de una organización vecinal ligada al PCF... A la segunda reunión no quedaba más que 12 personas...

(Presidenta de la asociación de jardines infantiles, comunicación personal, 21 de febrero de 2011)

Después de este episodio, la pareja y un núcleo de vecinos continuaron cooperando de manera autónoma e informal durante una década, organizando sus actividades educativas y recreativas en sus propios apartamentos o en un local perteneciendo a la colectividad del monoblock. El control de la asociatividad local por medio de los militantes comunistas era importante en todos los barrios de Gennevilliers (Dupuy, 2003; Masclet, 2003), algo que corroboraba el intendente comunista electo en 2014, quien era responsable de la sección local del partido en los años 1980-1990.

Hay barrios donde era realmente la omnipresencia del PCF... no había nada más que monoblocks en los cuales contábamos por lo menos una célula, es decir una organización comunista por edificio. A lo mejor, creábamos una asociación vecinal de más, era la única asociación que podía existir... en fin, había dos asociaciones que existían en los barrios, la cooperadora escolar y la unión vecinal. Todo esto dirigido por comunistas, era realmente la omnipresencia. (...) Yo contaba el número de comunistas por cada escalera de monoblocks, mi objetivo era: una escalera, un comunista. Para hacer una cuadrícula social importante. Llegábamos a cuadricular, hacíamos una malla social extremadamente importante.

(Intendente de la ciudad de Gennevilliers, comunicación personal, 10 de marzo de 2010). 
La fuerza del sistema sociopolítico de la banlieue rouge reposaba entonces sobre una valoración y predominancia del grupo obrero, una simbiosis entre el barrio y la fábrica, un tejido social estrechamente controlado por militantes comunistas y un trabajo de homogeneización del conjunto de organizaciones políticas, sindicales y asociativas por medio del partido comunista (Mischi, 2014). Como veremos en la tercera parte, el sistema comunista empieza a desagregarse a fines de los años 70 con el debilitamiento de cada uno de sus fundamentos.

\subsection{El conurbano y las vicisitudes del peronismo}

El desarrollo industrial de la Argentina difiere netamente del de Francia, y la conformación de los territorios populares en el conurbano bonaerense nos devuelve a otros tipos de configuraciones políticas y sociabilidades locales. La expansión del área metropolitana de Buenos Aires se inicia a partir del último tercio del siglo XIX (Scobie, 1974; Gorelik, 1998) como consecuencia del empuje económico y demográfico vinculado con la instalación del modelo agroexportador, la inversión de capitales extranjeros y la migración de trabajadores europeos (Rocchi, 2000; Devoto, 2002). En la ciudad de Buenos Aires, nuevos barrios emergieron hacia el oeste sin una verdadera homogeneidad social y formaron el crisol de una "nueva cultura popular y barrial" (Gutiérrez y Romero, 1989 y 2007) al interior de la cual las uniones vecinales y sociedades de fomento jugaron un rol a la vez social y político (De Privitellio, 2003). Desde fines del siglo XIX, la red ferroviaria había permitido también la constitución de pueblos fuera de la avenida General Paz en los que se radicaron un espectro heterogéneo de sectores sociales con movilidad ascendente, tal como se observa en Caseros (localidad cabecera del distrito de Tres de Febrero) alrededor de la estación del ferrocarril San Martín. Con el despegue industrial luego de la crisis de 1929 y las políticas desarrollistas de los años 1950-1960, el conurbano empieza a tener sus rasgos urbanos y populares a medida que fábricas, talleres y migrantes internos se instalan en los centros periféricos estructurados por los tres brazos del ferrocarril que unen la ciudad de Buenos Aires con el interior de la provincia y el país (Rougier y Pampin, 2015). En estos territorios se gestó gran parte de la constitución de una clase obrera y del advenimiento del peronismo (Torre, 1989; Lobato, 2001; Plotkin, 2012). Como señala Adrián Gorelik, "el peronismo se identificó con los habitantes de esta nueva periferia, al punto de que su llegada al poder pudo ser representada como una 'toma de la ciudad' por las nuevas multitudes 'mestizas' que se habían estado formando 'extramuros”' (Gorelik, 2015, p. 44). Esta estrecha relación entre el peronismo y la población del Gran Buenos Aires se manifestó claramente durante las elecciones de 1946, pues la fórmula encabezada por Perón superó el $50 \%$ de los votos positivos en todos los municipios del emergente suburbio (Bisso, 2015).

Durante el peronismo clásico, a la par de la banlieue rouge parisina, las configuraciones políticas en el conurbano bonaerense se asemejan al modelo clásico de las periferias populares cuya organización social articula una comunidad popular y una conciencia de clase obrera, en torno de un sistema político municipal (Kessler, 2015). Entre 1946 y 1955, si bien las organizaciones sindicales ocuparon una posición central dentro del sistema peronista, las organizaciones territoriales del partido -las unidades básicas- jugaron un rol importante en la movilización de las clases populares (Acha y Quiroga, 2015). La "carta orgánica" de 1954 define las organizaciones básicas como "el organismo primario permanente, la célula de base, el centro elemental de adoctrinamiento, de difusión y de desarrollo del peronismo, encargado de la afiliación, la adhesión y la formación de peronistas" (Quiroga, 2008, p. 12). Estas organizaciones estaban encargadas de animar la vida partidaria a nivel local (elección de delegados, movilizaciones electorales) y de servir de intermediarias entre las asociaciones vecinales y el Estado (Acha, 2004). Las unidades de base femeninas encuadradas por militantes ligadas al partido peronista femenino y la Fundación Eva Perón servían también de relevo para canalizar las demandas de asistencia social e intervenir en caso de ser necesario (Romero, 2002; Barry, 2009). A lo largo de los dos primeros gobiernos peronistas, las configuraciones políticas locales en las ciudades del conurbano reposaban entonces sobre la imbricación de diferentes organizaciones (sindicatos, 
partidos políticos, unidades básicas, Fundación Eva Perón, asociaciones vecinales) según una estructura esencialmente verticalista, que las ligaba directamente a los vértices del Estado (Mustapic, 2002).

El golpe de Estado de 1955 y la proscripción del peronismo precipitó la disociación de las distintas organizaciones populares y resulta difícil mantener la perspectiva de un sistema social en los territorios del conurbano. Las organizaciones gremiales constituyeron el principal espacio de movilización de la clase obrera (James, 1990), pero con una radicación en los lugares de trabajo mientras los barrios se estructuraban en torno a un asociacionismo relacionado sobre todo con problemas de hábitat (Kessler, 2004). Es efectivamente en la segunda mitad del siglo XX que el Gran Buenos Aires conoció su mayor expansión urbana y demográfica, pues su heterogénea población pasó de 1,7 millones de habitantes en 1947 a 8,7 millones en 1980. Las intermitencias y ambigüedades de las políticas urbanas desembocaron en el acceso masivo de las clases populares a la propiedad, pero con un grave déficit infraestructural que muchas asociaciones barriales -más o menos formalizadas- intentaron reducir por medio de la ayuda mutua y el reclamo al Estado (Armus y Bohoslavsky, 2015).

Como lo relata la referente del Movimiento Evita en Tres de Febrero, estas prácticas asociativas estuvieron muy presentes en las villas miseria del Área Metropolitana de Buenos Aires durante los años 1960-1970, y siguen siendo centrales en la organización sociopolítica de los barrios más carenciados. Esta dirigente social se formó a la militancia a través de movilizaciones para la vivienda e intenta transmitir hoy en día esos aprendizajes a los vecinos que se acercan al Movimiento Evita.

Yo tengo una historia de familia militante... Nací en una villa miseria y lo primero que hacía la gente en el barrio era juntarse
para pedir una vivienda definitiva. Y esa villa se juntó con otra villa y esas dos se juntaron con otras y formaron una comisión
intervilla. Entonces una vez que nos juntamos todos, fueron al Instituto de la vivienda y dijeron: "nosotros queremos la
vivienda definitiva". Estuvieron sus años pero la consiguieron. Entonces les contó a los vecinos esta experiencia, que los
vecinos organizados y con un objetivo pueden pedir la vivienda e ir por más... La idea es esa, ir por más... No pedir la olla
popular... pero sí la vivienda, el gas, lo que se necesita. (...) Por ejemplo, el viernes pasado nos juntamos con los vecinos de un
barrio, los que son referentes del merendero, de la olla popular, de la comisión de vecino, de la cooperativa... nos juntamos a
ver lo que se necesita. Les digo a los vecinos: eque sería lo más urgente acá? Y una me dice que lo más urgente es la vivienda
pero ella siente que no lo pueden dar una repuesta. Bueno le digo, no importa, lo tomamos... porque si es la vivienda, nos
juntamos con diez vecinos, armamos una comisión y nos juntamos con otros barrios que armen una comisión como fue en mi
época y vamos tres o cuatro barrios al Ministerio de Desarrollo para preguntar: ¿cómo hacemos para conseguir la vivienda?
No nos va a ser fácil pero tenemos un camino, tenemos una manera de plantearlo.
(Referente local del Movimiento Evita, comunicación personal,19 de agosto de 2010).

Otros procesos que contribuyeron a la focalización de las asociaciones populares locales en el hábitat y de ahí a su relativa autonomización de las organizaciones partidarias y gremiales- fueron la implantación de grandes industrias en el segundo y tercer cordón del conurbano y el desarrollo de un transporte público subsidiado (el ferrocarril y el colectivo) que contribuyeron a solucionar el problema del alejamiento entre la residencia y el trabajo, manifiesto en los largos tiempos de viaje necesarios para acceder a las fuentes laborales (Di Virgilio, Guevara y Arqueros Mejica, 2015). Estos datos resultan fundamentales para diferenciar las configuraciones políticas y las sociabilidades locales en las periferias populares de París y Buenos Aires entre los años 1950 y 1970. Cuando las ciudades obreras del cordón parisino se definen por una simbiosis entre el barrio y la fábrica y la imbricación de las sociabilidades políticas, sindicales y asociativas, los distritos populares del conurbano se distinguen por una sociabilidad local centrada prioritariamente en problemas de la vivienda, y relativamente desligada de las cuestiones del trabajo y de la política. La importancia de este tipo de asociacionismo en el conurbano se manifestó especialmente en las movilizaciones de los años 1990 y 2000 en contra del orden neoliberal introducido por el gobierno peronista de Carlos Menem y acompañado por los principales sindicatos. 


\section{Desagregación DEL MUNDo OBRERo Y RELEVANCIA DE LA PARTICIPACIÓN ASOCIATIVA}

La incorporación de las diferencias históricas respecto de las formas de sociabilidad local en las periferias populares de París y Buenos Aires se presenta como esencial para analizar, a la vez, los contrastes entre las movilizaciones sociales a lo largo de las últimas décadas y las similitudes en los mecanismos que fortalecen la participación asociativa en los barrios populares. A pesar de la diversidad de situaciones concretas, la investigación comparativa ilumina en ambos casos nacionales una tendencia común hacia un protagonismo mayor de las asociaciones locales en las configuraciones políticas de las periferias populares que reposa sobre la conjunción de un cúmulo de factores, cuya importancia es variable según el tiempo y el espacio. Entre los principales factores, la investigación destacó el debilitamiento de la sociedad salarial, la desagregación del mundo obrero, la desideologización del poder y la territorialización de la política.

\subsection{Colapso del sistema comunista y territorialización de las políticas sociales}

En el caso de la banlieue rouge parisina, la reconfiguración de territorios populares refleja los efectos de la desindustrialización, la desagregación del sistema comunista y la intervención estatal por medio de políticas sociales focalizadas. A partir de los años 70 , con el cierre de fábricas, la pérdida de empleos industriales y la pauperización de los barrios de vivienda social, "el patrimonio común del grupo obrero constituido en torno al barrio, la fabrica y las organizaciones políticas se desagregó” (Bacqué y Fol, 1997, p. 17). En estos territorios, la desafiliación de las clases populares ligada al debilitamiento de la sociedad salarial (Castel, 1995) se encuentra enlazada entonces con una desafiliación política e identitaria de la ciudad obrera (Bacqué y Sintomer, 2001). El Partido comunista francés atravesó también fuertes tensiones internas que aminoraron el trabajo de homogeneización partidaria y adelantaron la desarticulación de las distintas organizaciones del sistema comunista, como la retirada de numerosos militantes (Pudal, 2009; Mischi, 2014). Las redes comunistas perdieron progresivamente su influencia sobre las asociaciones locales que se diversificaron y se desarrollaron a través de relaciones de "cooperación" con el Estado a partir de los años 80.

La intervención creciente del Estado en los barrios desindustrializados y pauperizados de los suburbios constituye en efecto un elemento clave para entender el desarrollo de la participación asociativa. Elaborada en sintonía con las leyes de descentralización de 1982 y 1983, la Politique de la ville constituye un nuevo sistema de referencia de las políticas públicas que impide la cooperación entre el Estado central, las colectividades territoriales y las asociaciones vecinales para abordar de manera transversal y territorializada los problemas de hábitat, desempleo, pobreza, educación, salud, seguridad, etc. (Dubedout, 1983; Donzelot y Estèbe, 1994). De este modo, con una focalización en los llamados "barrios prioritarios", el programa "Desarrollo social de los barrios" de la Politique de la ville buscó fortalecer la participación de los vecinos y subvencionó una variedad de iniciativas asociativas.

El caso de Gennevilliers fue muy pertinente para analizar este profundo cambio de las sociabilidades locales y las configuraciones políticas, dado que la primera Comisión nacional del programa "Desarrollo social de los barrios" seleccionó en 1983 el barrio en el cual vivía el grupo de vecinas del monoblock que organizaba informalmente una red de solidaridad en torno a la guardia de los infantes. En este momento, con otro colectivo de mujeres del barrio vinculado al movimiento feminista, las mujeres del monoblock estaban movilizadas para hacer público el problema de la inserción social y laboral de las madres amas de casa, una causa que no había adquirido una verdadera legitimidad al interior del mundo comunista (Courtois y Lazar, 1995; Dupuy, 2009). Esta intervención en el espacio publico local fue retomada por los responsables del dispositivo "Desarrollo social de los barrios" que aportaron recursos humanos, financieros y materiales para que se abran y se consoliden bajo el formato asociativo una casa de mujeres, unos jardines infantiles y, años más tarde, un centro de capacitación y un hogar para mujeres víctimas de violencia. 
Además de la concesión de financiamiento público, la Politique de la ville permitió a estas asociaciones de mujeres gozar de una nueva legitimidad en la definición y resolución de problemas públicos locales, como aquellos ligados a la emancipación de las mujeres. Con el correr de los tiempos, cada una de esas asociaciones se fue independizando de las otras -aunque se mantuvieron cooperaciones y solidaridades en momentos oportunos- y sus actividades se desarrollaron bajo una reivindicación de autonomía respecto de las instituciones políticas.

En el caso de la asociación de jardines infantiles, cuyo núcleo dirigente está formado por el grupo de mujeres del monoblock, el proyecto asociacionista apuntaba a sacar a las madres del espacio doméstico, generar lazos de sociabilidad entre ellas y abrir camino hacia un empleo gracias a la valoración de los saberes prácticos adquiridos por sus propias experiencias de madre. La realización de una monografía de esta asociación, todavía vigente en el momento del trabajo de campo, permitió iluminar la dinámica de la participación asociativa en los barrios populares y el posicionamiento de este tipo de organización en la nueva configuración política. Con más de treinta años de actividad en distintos barrios de la ciudad, esta asociación logró gestionar un presupuesto de 1,5 millones de euros, lo que permitía mantener cinco jardines infantiles y cincuenta mujeres asalariadas. La asociación permitió a casi ochenta mujeres obtener el diploma de cuidadora de niños, maestra o enfermera. Como lo relata la directora de la asociación, las mujeres empezaban generalmente a participar de las actividades de manera voluntaria, seguían trabajando en el marco de una capacitación y eran reclutadas en la misma estructura o en otra después de adquirir el diploma. Este proceso facilitaba la integración de mujeres con bajos recursos socioeconómicos y favorecía la adhesión de aquellas a los valores y principios de la asociación.

Trabajamos mucho sobre la formación interna. Cuando la gente llega, no tienen necesariamente capacitaciones, pero se van a formar profesionalmente para tener diplomas. Y empiezan como voluntarias cuando dejan sus niños, aunque sea un día por semana. (...) Por ejemplo, Fátima estaba presente desde el inicio del proyecto y se capacitó como cuidadora de niños, después como maestra y ahora hace dos años que tiene el diploma de enfermera. Tratamos de trabajar así, para tener gente que intenta integrarse y estar bien en adecuación con el proyecto original.

(Presidenta de la asociación de jardines infantiles, comunicación personal, 21 de febrero de 2011).

La autonomía de esas asociaciones de mujeres fue obstaculizada, no obstante, por la difusión de normas provenientes de los poderes públicos. Una consecuencia mayor de la llamada "relación de cooperación" entre las administraciones públicas y las asociaciones es el involucramiento de aquellas en un proceso de isomorfismo institucional (Enjolras, 1996) que se define como "la tendencia mimética de las asociaciones a adoptar las formas organizacionales de las burocracias con las cuales interactúan regularmente" (Hély, 2009, p. 201). El proceso de isomorfismo institucional explica la propensión de las organizaciones sociales subvencionadas por medio de las políticas públicas a incorporar en su proyecto y funcionamiento las normas administrativas que condicionan su financiamiento. Como lo describe la coordinadora de la asociación de jardines infantiles, la actividad de los dirigentes asociativos tiende a focalizarse sobre cuestiones de gestión bajo una lógica de supervivencia de la organización, en perjuicio de cuestiones sociopolíticas ligadas a problemas del barrio. Como lo relataban varios miembros de la asociación, las relaciones con las administraciones públicas se sustituyeron progresivamente al contacto con los vecinos y los otros militantes sociales.

Con las otras asociaciones, nos juntamos cada vez menos... Estamos cada una con nuestras cosas y eso es muy triste. Estamos atareados por un costado administrativo que pasa a ser súper pesado porque tenemos que rendir cuentas extremadamente precisas. (...) Nos exigen mucho y no tenemos tiempo para nada. El exterior está abandonado desde cinco o seis años porque estamos atrapados por lo cotidiano.

(Coordinadora de la asociación de jardines infantiles, comunicación personal, 15 de febrero de 2011).

A pesar de un número creciente de asociaciones vecinales y de una nueva legitimidad para intervenir en los problemas públicos locales, la investigación puso de relieve una asimetría en las relaciones de poder entre las asociaciones y los poderes públicos, ya que estos últimos arman anualmente el llamado a proyectos para 
financiar actividades asociativas, eligen los temas estratégicos, imponen objetivos a cumplir y controlan la regularidad del funcionamiento de las organizaciones subvencionadas. Por ejemplo, los jardines infantiles tienen que cumplir reglas de higiene y seguridad estrictas que alejan el espacio de trabajo del modelo de la casa y ponen en dificultad a ciertas madres recientemente incorporadas a la organización y todavía no capacitadas para el oficio. No obstante, gracias a su anclaje en barrios carenciados y el reconocimiento de su trabajo social acerca de la inclusión de mujeres, las militantes asociativas tienen la capacidad de negociar unos márgenes de maniobra para cumplir con las normas sin desviarse totalmente de su proyecto original, lo que se traduce aquí en la tolerancia de un tiempo suplementario, acordado por los médicos y enfermeras del servicio público de Protección maternal e infantil, para que las nuevas integrantes adapten paulatinamente sus prácticas a las normas oficiales del sector. Como la gran mayoría de las asociaciones subvencionadas, esta organización no cae ni en la subordinación total, ni en la contestación radical, sino que entra en negociación con las administraciones públicas para conservar una autonomía relativa en cuanto a sus objetivos y modos de actuar (Nicourd, 2009).

\subsection{Pauperización de los sectores populares y territorialización de las políticas sociales}

En el caso del conurbano bonaerense, el análisis identificó la desindustrialización, la desindicalización del partido peronista y el desarrollo de políticas sociales focalizadas como principales factores de la reconfiguración de los territorios populares. Las reformas económicas iniciadas durante la última dictadura por el ministro Martínez de Hoz sellan el declive de la sociedad salarial argentina y la disminución del sector industrial en el producto nacional. El Gran Buenos Aires fue particularmente afectado por las políticas de reestructuración de la industria y sufrió en las décadas posteriores a la dictadura un proceso de desindustrialización, "con cierre de establecimientos y numerosas pérdidas de puestos de trabajo, que en algunas localidades modificaron de cuajo su fisionomía y cultura industrial" (Rougier y Pampin, 2015, p. 217). El debilitamiento del mundo obrero se manifestó también por medio de la desindicalización del partido justicialista (Levitsky, 2005) en el contexto del retorno a la democracia y de las reformas internas llevadas a cabo en las distintas provincias bajo el lema de la "renovación peronista" (Ferrari y Mellado, 2016). En fin, el surgimiento de una nueva pobreza que afecta a varios sectores de la población (Minujin, 1992; Minujin y Kessler, 1995) se acompañó del desarrollo de políticas sociales focalizadas, muchas veces de corto plazo, destinadas a resolver necesidades específicas (alimentación, salud, vivienda) o distribuir ingresos monetarios alternativos al empleo (Prévôt-Schapira, 1996; Falappa y Andrenacci, 2008). El conurbano bonaerense fue el territorio privilegiado de este nuevo tipo de planes sociales (Soldano y Costa, 2015), tanto por la concentración de pobreza como por el peso político de la región, que conllevó una expansión de redes políticas territorializadas usados por los vecinos como red de resolución de problemas (Auyero, 2001).

A partir de mediados de los años 90, en el contexto de una profundización de los procesos de precarización laboral y segregación socioespacial, el heterogéneo movimiento de trabajadores desocupados puso a la luz la centralidad del asociacionismo territorial y su dinámica asambleísta en las movilizaciones de las clases populares (Svampa y Pereyra, 2003; Svampa, 2008; Merklen, 2009). A través de confrontaciones y negociaciones con los poderes públicos, las diversas organizaciones piqueteras tuvieron un protagonismo en el espacio público y una influencia sobre el debate en torno a problemas públicos tales como el desempleo, la pobreza y la exclusión. A partir del año 2003, a medida que el alto crecimiento económico se acompañaba de una nueva regulación laboral, la conflictividad social bajó en intensidad y los sindicatos retomaron cierto protagonismo (Kessler y Merklen, 2013). No obstante, un conjunto de organizaciones sociales surgidas al calor de la protesta social ha mantenido una intensa actividad en los barrios populares (Kessler, Svampa, González Bombal, 2010; Quirós, 2011; Pérez y Natalucci, 2012; Vommaro, 2017), tanto en relación con las tradicionales políticas sociales de asistencia a individuos en situación de alta vulnerabilidad como en aquellas más recientes que se inscriben dentro del "giro productivo que busca absorber a la población 
asistida" (Cortés y Kessler, 2013) y apuntan a promover la inclusión a partir del desarrollo de la economía social (Perelmiter, 2016). Lejos de resumirse a una lógica clientelista (Vommaro, Combes, 2016), esta diversidad de organizaciones conforma redes de solidaridad en los territorios populares y participan de la puesta en marcha de políticas sociales focalizadas.

Para investigar sobre esta nebulosa asociativa y sus relaciones con las instituciones públicas dentro de las configuraciones políticas elegimos el caso del Movimiento Evita, que se constituyó en 2005 como aglomerado de varias organizaciones sociales con el fin de participar en la conformación de un espacio militante kirchnerista y se especializó a partir de 2008 en el desarrollo de la economía social (Natalucci, 2012). En Tres de Febrero, la organización local del Movimiento Evita empezó a crecer notablemente gracias a los recursos del "Programa Ingreso Social con Trabajo - Argentina Trabaja" del Ministerio de Desarrollo Social de la Nación, cuyo objetivo consistía en sustentar la creación de cooperativas en barrios carenciados que agrupaban a desempleados considerados como los más alejados del mercado de trabajo. Estas cooperativas realizaban esencialmente pequeñas obras relacionadas con la renovación de edificios públicos y el mejoramiento de la infraestructura en los barrios (calles, veredas, plazas, etc.). En 2008, al inicio del programa piloto, el Movimiento Evita en Tres de Febrero gestionaba doce cooperativas de dieciséis trabajadores cada una, lo que correspondía al mismo número de subsidios manejado por la municipalidad (n=192). Entre 2009 y 2010, la magnitud de los recursos fue en aumento y el crecimiento de la organización fue exponencial: los militantes gestionaban cerca de 1000 subsidios a través cooperativas de mayor envergadura que alcanzaban los sesenta trabajadores, y en algunos casos hasta trescientos.

Además de concebir el periodo kirchnerista como una "nueva etapa de la democracia”, los dirigentes locales del Movimiento Evita subrayaban la importancia de participar en políticas sociales que intentaban solucionar problemas más allá de las necesidades básicas. Para estos militantes, la alianza con el gobierno nacional se articula con trayectorias militantes que presentan rupturas y bifurcaciones vinculadas con momentos críticos de represión bajo la dictadura militar y de sobrevivencia bajo el orden neoliberal.

En la villa donde yo vivía, todos sabíamos que se podía pelear por la vivienda, por la vereda... y cuando tuvimos la vivienda, faltaba la luz y todos íbamos a pedir la luz... faltaba el agua, todos íbamos a pedir el agua. Hasta que bueno, la dictadura militar mató mucha gente... todos los compañeros de mi barrio, los militantes de la conducción, los vecinos que yo admiraba... para mi el héroe no era San Martin, era el vecino tal que después lo mataron. A todos esos vecinos que eran muchísimos, los mataron o desaparecieron... y nosotros quedamos como paralizados, quedamos viendo que hacer eso, luchar y pedir, estaba mal porque los mataban... pero después retomamos y este gobierno fue uno de los que nos devolvió esta esperanza, esta posibilidad de volver a luchar juntos, esta construcción popular del vecino, de las agrupaciones de abrir las puertas. Eso fue mejorando con este proceso, de 2003 para acá. (...) Con todo el proceso del neoliberalismo, lo que nos llevó fue a cada uno refugiarnos en su hogar para sostenerlo. Porque había desocupación, había muchas crisis... Toda la época del neoliberalismo fue una época mucho más dura porque cerraban las fabricas, había mucha desesperación... A raíz de esta nueva etapa de la democracia que empezó en 2003, hubo como más perspectivas, como una esperanza nueva de que podemos juntarnos y volver a hacer militancia... es decir cambiar la realidad de mucha gente, no solamente por mí, sino de los que están peor. Pasar de la resistencia a la construcción, y no estar más en el piquete, en el corte de ruta, a pedir las cosas básicas. Parar de sobrevivir y luchar por otra cosa: el trabajo digno, la salud, la educación.

(Referente local del Movimiento Evita, comunicación personal, 19 de agosto de 2010).

En comparación con el caso de las asociaciones de Gennevilliers, las interacciones de aquellas agrupaciones del Movimiento Evita parecían más vinculadas a las instituciones partidarias que a las administraciones burocráticas. Para profundizar este aspecto, el análisis se focalizó sobre el uso del poder discrecional de los militantes sociales que cumplían el rol de intermediarios de las políticas sociales. Como muchos dispositivos de asistencia social, el "Programa Ingreso Social con Trabajo" no cubría la totalidad de los beneficiarios potenciales, ${ }^{5}$ lo que imponía una selección de los demandantes a partir de criterios más o menos explícitos. Por un lado, la ley definía quiénes podían recibir esta ayuda: aquellos que no tenían trabajo ni percibían subsidio alguno. Por otro lado, los militantes agregaban otros criterios propios, en sintonía con las estrategias locales y nacionales del movimiento, como por ejemplo, privilegiar en el proceso selectivo a los jóvenes que tenían por 
lo menos dos hijos. Los militantes repartían también los cupos de manera tal que cubrieran todas las zonas populares del municipio. La selección de los beneficiarios se realizaba a través de relaciones personales de los militantes que actuaban principalmente en sus propios barrios con la legitimidad del conocimiento íntimo del vecindario.

Nos coordinamos con nuestros compañeros de cada barrio, que son los que eligen aquellos que vamos a anotar. Nosotros
hemos dividido el número de cupos por barrio. Lo que hacemos es discutir un criterio: primero que el no tenga trabajo...
después el que tenga más hijos... prioridad tienen los jóvenes... todo este tipo de cosas. Entonces discutimos un criterio y
después cada compañero en su barrio conoce a los vecinos y sabe la ansiedad que tienen. Por ejemplo, en el barrio de Joaquín,
es él el que va a saber a quién tiene que anotar. Otro compañero va a saber a quién anotar en su barrio y los otros también.
Entonces el criterio que usamos es repartir el poder y que los vecinos tengan el poder de decir: "tengo 30 cupos, yo sé a
quién les voy a proponer". El compañero del barrio dice también: "este puede ser presidente, este puede ser capataz... este
coordinador".

(Militante A del Movimiento Evita, comunicación personal, 17 de agosto de 2010).

Para reclutar a los responsables de cada cooperativa, ${ }^{6}$ los dirigentes locales del Movimiento Evita escogieron a los candidatos que se comprometían para militar en los barrios y realizar actividades comunitarias, adicionando nuevos criterios a los ya descriptos en el apartado anterior. De este modo, la organización pudo profundizar su vínculo con los vecinos y fomentar comedores, centros de jubilados, centros culturales, clubes deportivos, murgas, puestos sanitarios, talleres de alfabetización, etc. Como muchas redes sociopolíticas, los militantes aseguraron también la distribución de productos alimentarios de base a las familias más desfavorecidas. Gracias a los recursos del "Programa Ingreso Social con Trabajo" y a las prácticas asociativas en el territorio, la organización se nutrió y densificó. Por ello, produjo distintas jerarquías de adherentes al movimiento: a nivel local participaban treinta cuadros militantes que ejercían altas responsabilidades en la gestión del Programa, alrededor de cien simpatizantes comprometidos fuertemente con la organización que constituían su red territorial en los distintos barrios y participaban de las movilizaciones del grupo. A estos militantes y simpatizantes se sumaban los miles de trabajadores de las cooperativas a cargo de la organización local del Movimiento Evita, que eran adherentes de la organización.

La construcción de este tejido asociativo local permitió movilizar centenas de personas para distintos actos políticos. Algunos estaban asociados a momentos propios de la liturgia peronista como la celebración del día de la lealtad o la conmemoración de la muerte de Eva Perón. Otros estaban vinculados a la política nacional y los miembros de la organización eran convocados para manifestaciones de apoyo al gobierno en momentos de confrontación con la oposición, como fue el caso en 2009 con el matrimonio igualitario y la ley de medios. La valoración de estas movilizaciones era doble. Primero, eran testimonios de la adhesión al proyecto político y lealtad a los líderes Néstor y Cristina Kirchner. Segundo, eran demostraciones de su capacidad para movilizar masivamente a favor del gobierno. La referente local relata cómo incitaba a los "compañeros" a participar en esas movilizaciones y en qué medida el número de participantes era importante para negociar más cupos con las dirigencias nacionales.

Cuando hay marchas... puede ser por muchas razones, una movilización por el aniversario de la muerte de Evita o para apoyar al gobierno porque le está presionando mucho la derecha... Para todo, nosotros apoyamos. Entonces decimos: "Compañeros, nosotros vamos el martes a hacer esta marcha, ¿quién quiere venir? El que quiere venir, tiene el día libre. El que no, va a trabajar". Y listo, no hay una presión porque antes se decía mucho acá que al que iba se lo pagaba, en el micro. (...) Pero decimos también: "si vamos a hacer una marcha por la conmemoración de la muerte de Evita, y en vez de ser 30 de Tres de Febrero somos 300, Tres de Febrero va a tener otra consideración al momento de plantearse: ‘'bueno a quien le damos cupos de trabajo?". Bueno, entonces, no hay una presión efectiva, del tipo "yo no te pago si no venís”. Yo doy esa explicación a los compañeros y eso hace que muchas veces se va tomando conciencia. Antes movilizábamos un micro y ahí, por ejemplo, para la última marcha, ¡fuimos con 14 micros! ¡ 14 micros! Para nosotros es un gran crecimiento.

(Militante B del Movimiento Evita, comunicación personal, 17 de agosto de 2010).

De manera conforme a nuestra problemática, el estudio de caso del Movimiento Evita en Tres de Febrero permitió ilustrar el rol creciente de las organizaciones sociales en la puesta en marcha de políticas 
sociales focalizadas y en la movilización de vecinos de barrios populares. No obstante, la autonomía de la organización y de su red asociativa en el territorio aparecía limitada por razones económicas y políticas. Por un lado, las actividades laborales de las cooperativas dependían del gobierno municipal que distribuía las obras, sin posibilidad de generar contrataciones con algunas otras organizaciones o personas. En este marco, las cooperativas constituyeron más unos espacios transitorios de socialización e inserción laboral para los beneficiarios que unas organizaciones productivas perdurables. Por otro lado, el número de cupos de trabajo estaba definido al nivel del Ministerio de Desarrollo Social de la Nación y condicionado, en parte, por la capacidad de movilización de la agrupación para participar en actos políticos de apoyo al gobierno nacional o de transmisión de la cultura peronista. Estas relaciones estrechas con el gobierno junto al poder discrecional de los militantes ponen en cuestión el régimen de acción pública en el cual se inscriben las asociaciones y los planes sociales. Sin referencia a un derecho social universal, la transferencia de subsidios puede asemejarse a un régimen de favores con el riesgo de fomentar relaciones asimétricas que obstaculizan el empoderamiento de los destinatarios de las políticas sociales, sean actores individuales o colectivos.

\section{ConcLUSIÓN}

A pesar de las diferencias de las situaciones concretas, la comparación de la participación asociativa en los barrios populares de las periferias de París y Buenos Aires iluminan procesos sociales que permiten comprender la importancia adquirida por las asociaciones locales en las formas de intervención de las clases populares en el espacio público. Desde un punto de vista general se ha observado al interior de configuraciones políticas el pasaje de una estructuración vertical a una estructuración horizontal. A nivel de los territorios populares, este cambio de configuración se comprende principalmente a través de cuatro procesos: la desagregación del mundo obrero, la desideologización del poder, la territorialización de la política y la autonomización de las organizaciones de base. Si estos procesos no deben ser considerados como finalizados, señalan una dinámica actual que marca las sociedades occidentales, incluso hasta en casos contrastados como el de Francia y Argentina.

A partir de los años 70, en ambos casos nacionales, los procesos de desindustrialización y de desagregación del mundo obrero se conjugan con el reforzamiento del anclaje territorial en las formas de sociabilidad y movilización de las clases populares. En un contexto de debilitamiento de los canales tradicionales de participación de los sectores populares, las asociaciones movilizan al nivel de los barrios e intervienen en el espacio público para revindicar una resolución de las situaciones problemáticas. El despliegue de políticas territorializadas, ligadas a la pauperización de los barrios populares, genera igualmente nuevos recursos para esas organizaciones. La mediación de las organizaciones sociales permite al Estado gozar de una legitimidad de proximidad para poner en marcha acciones de solidaridad hacía los territorios carenciados. La inscripción de las asociaciones locales en el marco de políticas sociales focalizadas trae aparejado efectos sobre sus autonomías, lo que permite resaltar las relaciones de interdependencia entre estas organizaciones y los poderes públicos. Las tensiones entre las asociaciones y las instituciones políticas están presentes en los dos casos estudiados, pero se expresan de manera distinta, siendo predominante una lógica burocrática en Francia que atrae los dirigentes asociativos hacia un trabajo administrativo, y una lógica partidaria en Argentina que lleva a los militantes sociales hacia un trabajo político. Estas tensiones expresan la permanencia del poder estructurante de lo político a pesar de que el Estado deja actuar en su lugar una diversidad de actores de la sociedad civil. Esta configuración ilustra una paradoja de la democracia contemporánea en el contexto de la globalización neoliberal: la creación de un mundo que a la vez se basa sobre un Estado infraestructural y pretende prescindir de lo político.

En Francia, la precoz institucionalización de la Politique de la ville y su continuación bajo los distintos gobiernos de turno ilustra el largo consenso de sus elites políticas sobre el fin del Estado proveedor y el auge de un Welfare mix. En esta perspectiva, la ley de Economía Social y Solidaria promulgada en 2014 es un 
ejemplo de la profundización constante de esta relación entre la acción pública y el mundo asociativo en el marco de las políticas sociales. En Argentina, el camino hacia una nueva arquitectura institucional en torno a políticas sociales aparece más sinuoso, con fuertes crisis socioeconómicas y discursos políticos muy opuestos. Sin embargo algunos dispositivos implementados por los gobiernos kirchneristas, como el "Programa Ingreso Social con Trabajo", han sido prolongados luego de las elecciones de 2015 y el cambio político. El gobierno nacional encabezado por Mauricio Macri lanzó el "Plan nacional de economía social CREER Y CREAR" que manifiesta una cierta continuidad con las políticas públicas del Ministerio de Desarrollo Social de la Nación de la etapa anterior. Por ello, luego de la crisis del 2001 y a pesar de las diferencias ideológicas de los gobiernos de turno, el caso argentino ejemplifica también el consenso que se ha consolidado sobre la necesidad de una creciente articulación entre el Estado y las organizaciones de la sociedad civil para lograr un desarrollo social que incluya a los sectores históricamente marginalizados. En particular, el fomento de cooperativas de trabajo, la capacitación de las poblaciones objeto de políticas y el mejoramiento de la tecnología productiva de los pequeños emprendedores constituyen las principales aristas de una matriz de desarrollo con inclusión que busca conjugar los distintos recursos que provienen del Estado, el mercado y la solidaridad comunitaria.

Finalmente, esta comparación internacional sobre la participación asociativa en los barrios populares ilumina la pertinencia de los estudios de casos fuertemente contrastados. Este ejercicio resulta doblemente pertinente para el método comparativo, ya sea en relación a las diferencias como a las semejanzas. Por una parte, obliga, de hecho, a tomar en cuenta las diferencias sistémicas entre las sociedades estudiadas y, por tanto, reconoce la pertinencia, al menos parcial, de la escala nacional en la comprensión de los fenómenos sociales. El análisis comparativo de casos contrastados reposa sobre la puesta en evidencia de las idiosincrasias que pretende, posteriormente, superar. Sin embargo, el espacio nacional no es definido según una visión que vendría a cosificar las culturas; por el contrario, es abordado en tanto contexto a partir de fenómenos sociales que se encuentran en el centro de la comparación. De manera inductiva, es a partir del análisis del juego de los actores y de sus interacciones que podemos "elegir" los sistemas sociales pertinentes para la investigación y modelizar las configuraciones que dan sentido a las situaciones estudiadas. Este método implica necesariamente el recurso a una variedad de escalas en el análisis, sin presumir de la preponderancia de un espacio social sobre otro. Por otra parte, la búsqueda de una dinámica común en casos muy diferentes permite liberarse de ciertas categorizaciones enraizadas en nuestros modos de pensar y arrojan una nueva luz sobre objetos y terrenos familiares. Lo inesperado está fuertemente presente en el análisis comparativo de casos muy contrastados, lo que favorece el sondeo del investigador y agudiza su reflexividad. El recurso a la historia resulta indispensable para actualizar procesos sociales similares y dar coherencia a un mismo fenómeno social, a pesar de las grandes disparidades a nivel de sus concretizaciones. Las idas y vueltas entre los diferentes casos enriquecen la comprensión de relaciones complejas al interior de configuraciones, hasta que un marco de comprensión general se diseña y otorga sentido al conjunto de elementos del análisis. Los casos estudiados son integrados en una misma generalidad, sin negar la importancia de sus diferencias. Los contrastes sirven, al contrario, para esclarecer la diversidad del mundo social y las diferentes adaptaciones institucionales a transformaciones sociales comunes.

\section{BibLiOgrafía}

Acha, O. (2004). Sociedad civil y sociedad política durante el primer peronismo. Desarrollo económico, 174, 199-230.

Acha, O. y Quiroga, N. (dirs.). (2015). Asociaciones y política en la Argentina del siglo veinte. Entre prácticas y expectativas. Buenos Aires: Prometeo.

Andolfatto, D. (dir.) (2007). Les Syndicats en France. Paris: La documentation française.

Armus, D. y Bohoslavsky, E. (2015). Vivienda popular y asociacionismo en la conformación del Gran Buenos Aires. En G. Kessler, El Gran Buenos Aires (pp. 493-520). Buenos Aires: Edhasa.

Aron, R. (1965). Démocratie et totalitarisme. Paris: Gallimard.

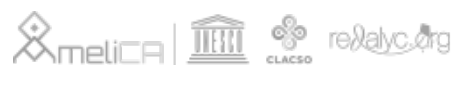


Annunziata, R. (dir.) (2015) ¿Hacia una mutación de la democracia? Buenos Aires: Prometeo.

Authier, J-Y., Bacqué, M-H. y Guérin-Pace, F. (dirs.) (2007). Le quartier. Enjeux scientifiques, actions politiques et pratiques sociales. Paris: La Découverte.

Auyero, J. (2001). La politica de los pobres. Las prácticas clientelistas del peronismo. Buenos Aires: Manantial.

Bacqué, M-H. y Fol, S. (1997). Le devenir des banlieues rouges. Paris: L'Harmattan.

Bacqué, M-H. y Sintomer, Y. (2001). Affiliations et désaffiliations en banlieue. Réflexions à partir des exemples de Saint-Denis et d'Aubervilliers. Revue française de sociologie, 42, 217-249.

Bacqué, M-H., Rey, H. y Sintomer, Y. (dirs.) (2005). Gestion de proximité et démocratie participative. Une perspective comparative. Paris: La découverte.

Barry, C. (2009). Evita capitana: El Partido Peronista Femenino 1949-1955. Tres de Febrero: Editorial Untref.

Barthélemy, M. (2000). Associations : un nouvel âge de la participation? Paris: Presses de Sciences Po.

Beaud, S. y Pialoux, M. (1999). Retour sur la condition ouvrière. Paris: Fayard.

Bevort, A. (2002). Pour une démocratie participative. Paris: Presses de Sciences Po.

Bisso, M. (2015). Conurbano bonaerense: votos y política en el siglo XX. En G. Kessler, El Gran Buenos Aires, Buenos Aires (pp. 315-342). Buenos Aires: Edhasa

Bloch, M. (1928). Pour une histoire comparée des sociétés occidentales. Revue de synthèse historique, 46, 15-50.

Blondiaux, L. (2008). Le nouvel esprit de la démocratie. Paris: Seuil.

Blumer, H. (2004) [1971]. Les problèmes sociaux comme comportements collectifs. Politix, 67, 189-199.

Briquet, J-L. y Sawicki, F. (1989). L'analyse localisée du politique. Politix, 7, 6-16.

Carrel, M. (2013). Faire participer les habitants? Citoyenneté et pouvoir d'agir dans les quartiers populaires. Lyon: ENS Éditions.

Castel, R. (1995). Les métamorphoses de la question sociale. Une chronique du salariat. Paris: Fayard.

Castoriadis, C. (1973). La société bureaucratique. Tomes I et II. Paris: Union générale d'éditions.

Cefaï. D. (2007). Vers un nouveau désordre mondial : politique comparée et anthropologie pluraliste selon Clifford Geertz. Critique internationale, 36(3), 169-180.

Cefaï, D. y Terzi, C. (2012). L'expérience des problèmes publics. Paris: EHESS.

Compagnon, O. (2009). L'Euro-Amérique en question. Comment penser les échanges culturels entre l'Europe et l'Amérique latine ? Nuevo Mundo Mundos Nuevos [En línea]. Recuperado de http://nuevomundo.revues.org/ 54783.

Cortés, R. y Kessler, G. (2013). Políticas, ideas y expertos en la cuestión social de la Argentina democrática (1983-2012). Revista de Indias, 257, 239-264.

Courtois, S. y Lazar, M. (1995). Histoire du Parti communiste français. Paris: PUF.

De Privitellio, L. (2003). Vecinos y ciudadanos. Política y sociedad en la Buenos Aires de entreguerras. Buenos Aires: Siglo XXI.

Demazière, D., Giraud, O. y Lallement, M. (2013). Comparer. Options et inflexions d'une pratique de recherche. Sociologie du travail, 55(2), 136-151.

Détienne, M. (2000). Comparer l'incomparable. Oser, expérimenter et construire. Paris: Seuil.

Devoto F. (2002). Historia de la inmigración en la Argentina. Buenos Aires: Editorial Sudamericana.

Dewey, J. (2010) [1927]. Le public et ses problèmes. Paris: Gallimard.

Di Stefano, R., Sabato, H., Romero, L. A. y Moreno, J. L. (2002). De las cofradias a las organizaciones de la sociedad civil. Historia de la iniciativa asociativa en Argentina. Buenos Aires: Edilab.

Di Virgilio, M. M., Guevara T. y Arqueros Mejica, S. (2015). La evolución territorial y geográfica del conurbano bonaerense. En G. Kessler, El Gran Buenos Aires (pp. 73-102). Buenos Aires: Edhasa.

Donzelot, J. y Estèbe, P. (1994). L'État animateur. Essai sur la politique de la Ville. Paris: Éditions Esprit. 
Arnaud Trenta. La participación popular bajo El prisma de la comparación de casos contrastados: as...

Dubedout H. (1983). Ensemble, refaire la ville : Rapport au Premier Ministre du Président de la commission nationale pour le développement social des quartiers. Paris: La Documentation française.

Dubet, F. y Lapeyronnie, D. (1992). Les Quartiers d'exil. Paris: Le Seuil.

Dupuy, C. (2003). Un bastion communiste de la banlieue parisienne: Gennevilliers, années 1920 - fin des années 1960. (Tesis de doctorado). Universidad Paris XIII.

Dupuy, C. (2009). Les angles morts de la mobilisation en territoire du communisme. Les déconvenues de l'engagement militant et protestataire à Gennevilliers (1950-1960). Actes des Journées sur les Territoires du Communisme. Paris: Université Paris 1 Panthéon-Sorbonne, 01-02 de diciembre.

Durkheim, É. (1895). Les règles de la méthode sociologique. Paris: Alcan.

Durkheim, É. (1897). Le suicide. Étude de sociologie. Paris: Alcan.

Enjolras, B. (1996). Associations et isomorphisme institutionnel. Recma, 261, 68-76.

Etchemendy, S. (2013). La "doble alianza" gobierno-sindicatos en el kirchnerismo (2003-2012). Orígenes, evidencia y perspectivas. En C. H. Acuña (ed.), ¿Cuánto importan las instituciones? Gobierno, Estado y actores en la política argentina (pp. 291-324). Buenos Aires: Siglo XXI.

Falappa, F. y Andrenacci, L. (2008). La a politica social de la Argentina democrática (1983-2008). Los Polvorines: UNGS.

Ferrari, M. y Mellado, M. V. (dirs.) (2016). La renovación peronista. Organización partidaria, liderazgos y dirigentes, 1983-1991. Tres de Febrero: Eduntref.

Fourcaut, A. (1986). Bobigny, banlieue rouge. Paris: Éditions Ouvrières.

Fourcaut, A. (2007). Les banlieues populaires ont aussi une histoire. Projet, 299, 7-15.

Gauchet, M. (1985). Le désenchantement du monde. Une histoire politique de la religion. Paris: Gallimard.

Gauchet, M. (2001). Croyances religieuses, croyances politiques. Le débat, 115, 3-12.

Gauchet, M. (2003). La condition historique. Paris: Gallimard.

Gauchet, M. (2005). La condition politique. Paris: Gallimard.

Gauchet, M. (2007a). L'avènement de la démocratie I. La révolution moderne, Paris: Gallimard.

Gauchet, M. (2007b). L'avènement de la démocratie II. La crise du libéralisme, 1880-1914. Paris: Gallimard.

Gauchet, M. (2010). L'avènement de la démocratie III. À l'épreuve des totalitarismes, 1914-1974. Paris: Gallimard.

Gauchet, M. (2017). L'avènement de la démocratie IV. Le nouveau monde. Paris: Gallimard.

Geertz, C. (1968). Islam Observed: Religious Development in Morocco and Indonesia. Chicago: University of Chicago Press.

Geertz, C. (1983). Local Knowledge: Further Essays in Interpretative Anthropology. New York: Basic Books.

Geertz, C. (1998). The World in Pieces. Focaal - European Journal of Anthropology, 32, 91-117.

Giraud, O. (2003). Le comparatisme contemporain en science politique : entrée en dialogue des écoles et renouvellement des questions. En M. Lallement y J. Spurk (dirs.), Stratégies de la comparaison internationale (pp. 87-106). Paris: CNRS Éditions.

Giraud, O. (2012) Les défis de la comparaison à l'âge de la globalisation : pour une approche centrée sur les cas les plus différents inspirée de Clifford Geertz. Critique internationale, 57, 89-110.

Gorelik, A. (1998). La grilla y el parque. Espacio público y cultura urbana en Buenos Aires, 1887-1936. Bernal: Universidad nacional de Quilmes.

Gorelik, A. (2015). Terra incognita. Para una comprension del Gran Buenos Aires como Gran Buenos Aires. En G. Kessler, El Gran Buenos Aires (pp. 21-69). Buenos Aires: Edhasa.

Guerra, F-X. (2002). L'Euro-Amérique : constitution et perceptions d'un espace culturel commun. Actes du Colloque sur les Civilisations dans le Regard de l'Autre. Paris: Unesco.

Gusfield, J. (2009) [1981]. La culture des problèmes publics. L'alcool au Volant : la production d'un ordre symbolique. Paris: Économica. 
Gutiérrez, L. y Romero, L. A. (1989). Sociedades barriales, bibliotecas populares y cultura de los sectores populares, 1920-1945. Desarrollo Económico, 113, 33-62.

Gutiérrez, L. y Romero, L. A. (2007). Sectores populares, cultura y política. Buenos Aires en la entreguerra. Buenos Aires: Siglo XXI.

Hassenteufel, P. (2000). Deux ou trois choses que je sais d'elle. Remarques à propos d'expériences de comparaisons européennes. En CURAPP, Les méthodes au concret (pp. 105-124). Paris: PUF.

Hély, M. (2009). Les métamorphoses du monde associatif. Paris: PUF.

Ion, J. (1997). La fin des militants? Paris: L'Atelier.

Ion, J. (2012). S'engager dans une société d'individus. Paris: Armand Colin.

James, D. (1990). Resistencia e integración. El peronismo y la clase trabajadora argentina. Buenos Aires: Sudamericana.

Kessler, G. (2004). Sociología del delito amateur. Buenos Aires: Paidós.

Kessler, G. (2012). Las consecuencias de la estigmatización territorial: Reflexiones a partir de un caso particular. Espacios en blanco, 22(1), 165-197.

Kessler, G. (2014). Controversias sobre la desigualdad. Argentina 2003-2013. Buenos Aires: Fondo de cultura económica.

Kessler, G. (dir.) (2015). El Gran Buenos Aires. Buenos Aires: Edhasa.

Kessler, G., Svampa, M. y Gonzalez Bombal, I. (dirs.) (2010). Reconfiguraciones del mundo popular. El Conurbano Bonaerense en la postconvertibilidad. Buenos Aires: Prometeo.

Kessler, G. y Merklen, D. (2013). Una introducción cruzando el Atlántico. En R. Castel, G. Kessler, D. Merklen y N. Murard, Individuación, precariedad, inseguridad. ¿Desinstitucionalización del presente? (pp. 9-31). Buenos Aires: Paidós.

Kocka, J. (2013). Les approches comparées face à la globalisation. Sociologie du travail, 55(2), 237-244.

Kriegel, A. (1968). Les Communistes français: Essai d'ethnographie politique. Paris: Seuil.

Lallement, M. (2003). Pragmatique de la comparaison. En M. Lallement y J. Spurk (dirs.), Stratégies de la comparaison internationale (pp. 297-306). Paris: CNRS Éditions.

Lallement, M. y Spurk, J. (dirs.) (2003). Stratégies de la comparaison internationale, Paris: CNRS Éditions.

Laville, J-L. (2010). Politique de l'association. Paris: Seuil.

Lefort, C. (1981). L'invention démocratique: les limites de la domination totalitaire. Paris: Seuil.

Levitsky, S. (2005). La transformación del justicialismo: Del partido sindical al partido clientelista, 1983-1999. Buenos Aires: Siglo XXI.

Lobato, M.Z. (2001). La vida en las fábricas. Trabajo, protesta y politica en una comunidad obrera, Berisso (1904-1970). Buenos Aires: Prometeo.

Manin, B. (1995). Principes du gouvernement représentatif. Paris: Flammarion.

Masclet, O. (2003). La gauche et les cités. Enquête sur un rendez-vous manqué. Paris: La Dispute.

Merklen, D. (2009). Quartiers populaires, quartiers politiques. Paris: La Dispute.

Minujin, A. (1992). Cuesta abajo: los nuevos pobres: efectos de la crisis en la sociedad argentina. Buenos Aires: Losada.

Minujin, A. y Kessler, G. (1995). La nueva pobreza en la Argentina. Buenos Aires: Planeta.

Mischi J. (2014). Le Communisme désarmé. Le PCF et les classes populaires depuis les années 1970. Marseille: Agone.

Murillo, M. V. (2005). Sindicatos, coaliciones partidarias y reformas de mercado en América Latina. Buenos Aires: Siglo XXI.

Mustapic, A. M. (2002). Del partido peronista al partido justicialista. Las transformaciones de un partido carismático. En M. Cavarozzi y J. M. Abal Medina (dirs.), El asedio a la politica. Los partidos latinoamericanos en la era neoliberal (pp. 137-161). Rosario: Homo Sapiens. 
Arnaud Trenta. La participación popular bajo el prisma de la comparación de casos contrastados: as...

Natalucci, A. (2012). Los movimentistas. Expectativas y desafíos del Movimiento Evita en el espacio kirchnerista (2003-2010). En G. Pérez y A. Natalucci (dirs), Vamos las bandas. Organizaciones y militancia kirchnerista (pp. 27-53). Buenos Aires: Trilce.

Nicourd, S. (2009). Éducation populaire : organisation du travail associatif et action publique. Entreprises et histoire, $56,62-72$.

Perelmiter, L. (2016). Burocracia plebeya. La trastienda de la asistencia social en el Estado argentino. San Martin: Editorial Unsam.

Pereyra, S. (2013). Política y transparencia. La corrupción como problema público. Buenos Aires: Siglo XXI.

Pérez, G. y Natalucci, A. (dirs) (2012).Vamos las bandas. Organizaciones y militancia kirchnerista. Buenos Aires: Trilce.

Plotkin, M. (2012). El día que se inventó el peronismo. La construcción del 17 de octubre. Buenos Aires: Sudamericana.

Prévôt-Schapira, M. F. (1996). Las políticas de lucha contra la pobreza en la periferia de Buenos Aires, 1984-1994. Revista Mexicana de Sociología, 58(2), 73-94.

Pudal, B. (1989). Prendre parti. Pour une sociologie historique du PCF. Paris: Presses de Sciences-Po.

Pudal, B. (2009). Un monde défait. Les communistes français de 1956 à nos jours. Paris: Éditions du croquant.

Quiroga, N. (2008). Las Unidades Básicas durante el primer peronismo. Cuatro notas sobre el Partido Peronista a nivel local. Nuevo Mundo Mundos Nuevos, [En línea]. Recuperado de: nuevomundo.revues.org/30565

Quirós, J. (2011). El porqué de los que van. Peronistas y piqueteros en el Gran Buenos Aires (una antropología de la politica vivida). Buenos Aires: Antropofagia.

Rocchi, F. (2000). El péndulo de la riqueza: la economía argentina en el período 1880-1916. En M. Z. Lobato (ed.), Nueva historia argentina (pp. 56-62). Buenos Aires: Sudamericana.

Roitter, M. y Gonzalez Bombal, I. (dirs.) (2000). Estudios sobre el sector sin fines de lucro en Argentina. Buenos Aires: Cedes.

Romero, L. A. (2002). El Estado y las corporaciones, 1920-1976. En R. Di Stefano, H. Sabato, L. A. Romero, y J. L. Moreno, De las cofradías a las organizaciones de la sociedad civil. Historia de la iniciativa asociativa en Argentina (pp. 169-275). Buenos Aires: Edilab.

Rosanvallon, P. (2004). Le modèle politique français. La société civile contre lejacobinisme de 1789 à nosjours. Paris: Seuil. Rosanvallon, P. (2006). La contre-démocratie. La politique à l'âge de la défiance. Paris: Seuil.

Rougier M. y Pampin G. (2015). Orígenes y esplendor de la industria en el Gran Buenos Aires. En G. Kessler, El Gran Buenos Aires (pp. 195-223). Buenos Aires: Edhasa.

Sawicki, F. (1997). Les réseaux du parti socialiste. Sociologie d'un milieu partisan. Paris: Belin.

Schuster F., Naishtat, F., Nardacchione, G. y Pereyra, S. (2006). Tomar la palabra. Estudios sobre protesta social y acción colectiva. Buenos Aires: Prometeo.

Schwartz, O. (2011). Peut-on parler des classes populaires ? La vie des idées [En línea]. Recuperado de laviedesidees.fr/ Peut-on-parler-des-classes.html

Scobie, J. (1974). Buenos Aires: Plaza to suburb, 1870-1910. New York: Oxford University Press.

Soldano D. y Costa, M. I. (2015). El conurbano bonaerense como territorio asistido. Pobreza, crisis y planes sociales. En G. Kessler, El Gran Buenos Aires (pp. 433-463). Buenos Aires: Edhasa.

Spector, M. y Kitsuse, J. (1977). Constructing social problems. Menlo Park: Cummings.

Svampa, M. (2008). Cambio de época. Movimientos sociales y poder político. Buenos Aires: Siglo XXI.

Svampa, M. (2011). Du "Qu'ils s'en aillent tous !" à l'exacerbation de la rhétorique nationale-populaire. Problèmes d'Amérique latine, 82, 77-91.

Svampa, M. y Pereyra, S. (2003). Entre la ruta y el barrio. La experiencia de las organizaciones piqueteras. Buenos Aires: Biblos.

Théret, B. (1997). Méthodologie des comparaisons internationales, approches de l'effet sociétal et de la régulation : fondements pour une lecture structuraliste des systèmes nationaux de protection sociale. L'année de la régulation, $1,163-228$. 
Torre, J. C. (1989) Interpretando (una vez más) los orígenes del peronismo. Desarrollo Económico, 112, 525-548.

Torre, J. C. (2003). Los huérfanos de la política de partidos. Sobre los alcances y la naturaleza de la crisis de representación partida. Desarrollo Económico, 168, 647-665.

Torre, J. C. (2017). Los huérfanos de la política de partidos (revisited). Panamá [En línea]. Recuperado de http://pa namarevista.com/los-huerfanos-de-la-politica-de-partidos-revisited/

Vommaro, G. (2017). Política popular en tiempos de economías postindustriales: trabajo territorial y economía moral en la Argentina reciente. Revista Pós Ciências Sociais, 14(27), 77-98.

Vommaro, G. y Combes, H. (2016). El clientelismo Politico, desde 1950 hasta nuestros dias. Buenos Aires: Siglo XXI.

Weber, M. (1996). Sociologie des religions. Paris: Gallimard.

Weber, M. (2001) [1909]. Économie et société dans l'antiquité. Paris: La Découverte.

Weber, M. (2014) [1922]. La ville. Paris: La Découverte.

\section{Notas}

1 Fuentes: Insee (censo de 2014) e Indec (censo de 2010).

2 Después de la caída de la junta militar en 1983, el partido Radical gobernó el municipio de Tres de Febrero de 1983 a 1987 y la alianza Cambiemos ganó las elecciones locales en 2015. De 1987 a 2015, el intendente fue un dirigente peronista.

3 Una asociación de mujeres en Gennevilliers que funda y administra jardines infantiles en distintos barrios con el objetivo de favorecer la inclusión social y laboral de las madres amas de casa, y una organización local del Movimiento Evita en Tres de Febrero que gestiona cooperativas de trabajo destinadas a los desempleados más alejados del mercado de trabajo a través del Programa Ingreso Social con Trabajo - Argentina Trabaja.

4 Una asociación de educación popular en Gennevilliers, fundada por exmilitantes comunistas, que apunta a la mayor difusión posible de los saberes críticos a través de clases y conferencias gratuitas, y una asociación cultural en Tres de Febrero, animada por jóvenes peronistas, que realiza murales en distintos barrios y propone formaciones a las artes por un costo reducido.

5 En un archivo de 2012 titulado "Rendimos cuentas", el Ministerio de Desarrollo Social de la Nación avanza un numero de 500.000 beneficiarios, pero sin explicitar la elaboración de esta cifra. En esta misma época, observando la situación socioeconómica desde la perspectiva de la heterogeneidad social, analistas subrayaban el crecimiento de un conjunto heterogéneo compuesto por trabajadores precarios, informales, con ingresos bajos, desocupados, subocupados, beneficiarios de planes sociales y sobreocupados con bajos ingresos, que alcanzan en total a la mitad de la población económicamente activa (Kessler, 2014).

6 Las cooperativas tienen su propia personería jurídica y los estatutos deben precisar como información mínima los apellidos del presidente y secretario de la organización. Las obras realizadas por las cooperativas son dirigidas por un capataz.

\section{BY-NC-SA}

